July 2005/28

\section{Policy development}

Statement of policy

This report is for information
This document sets our approach to promoting the sustainable development agenda following feedback received on our consultation document (HEFCE 2005/01). It includes a strategy statement and an action plan. We intend to review our approach by the end of 2007.

Sustainable

development in

higher education 


\section{Alternative formats}

This publication can be downloaded from the HEFCE web-site (www.hefce.ac.uk) under Publications. For readers without access to the internet, we can also supply it on 3.5" disk or in large print. Please call 01179317035 for alternative format versions.

\section{(C) HEFCE 2005}

The copyright for this publication is held by the Higher Education Funding Council for England (HEFCE). The material may be copied or reproduced provided that the source is acknowledged and the material, wholly or in part, is not used for commercial gain. Use of the material for commercial gain requires the prior written permission of HEFCE.

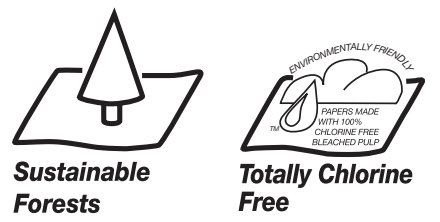




\section{Sustainable development in higher education}

To

Of interest to those responsible for
Reference
Publication date
Enquiries to

\author{
Heads of HEFCE-funded higher education institutions \\ Heads of universities in Northern Ireland \\ Strategic management, Governance \\ 2005/28 \\ July 2005 \\ Nicola Dowds \\ tel 01179317029 \\ e-mail n.dowds@hefce.ac.uk
}

\section{Executive summary}

\section{Purpose}

1. This document sets our approach to promoting the sustainable development agenda following feedback received on our consultation document (HEFCE 2005/01). We intend to review this approach by the end of 2007 .

\section{Key points}

2. Overall, the consultation exercise demonstrated:

a. A high degree of consensus that this agenda was important; that higher education (HE) had an important contribution to make to its delivery; and that HEFCE should have a role in facilitating the sector's activities in this area. With the marked exception of concerns around actions relating to the curriculum, the specific actions we suggested raised little negative comment.

b. A significant number of concerns about how we should promote this agenda, but with little consensus about the best way forward.

c. Agreement regarding the potential contribution by the HE sector to sustainable development through institutions':

- role as educators

- generation and transfer of knowledge

- leadership of, and influence on, local, national and international networks

- business strategy and operations.

3. This document comprises a new strategic statement accompanied by a slightly revised and updated version of our 
original action plan. The key revisions to the action plan are:

a. The removal of the proposal to 'explore with the Quality Assurance Agency, Universities UK (UUK) and the Standing Conference of Principals (SCOP) how a contribution to sustainable development could be used as an indicator of high quality taught provision'.

b. The insertion of a new action: 'To ask the Higher Education Academy, in the course of its ongoing work on sustainable development, to be alert to anything in the QAA precepts or codes that might work against including sustainable development in the curriculum, and if so to raise it with UUK, SCOP and the QAA.'

c. The inclusion of a new section on procurement, responding to feedback as well as to the high profile given to this issue in the Government's new strategy for sustainable development.

4. To help clarify HEFCE's interests in sustainable development we have developed a set of objectives for this first phase of activity. These will be to:

a. Seek 'win-win' opportunities for the sector to engage in this agenda by helping to identify sector-wide business cases as well as benefits for individual institutions.

b. Promote the value of engaging with the sustainable development agenda by integrating it in our policy-making processes and being open about the often hard choices made.

c. Demonstrate to stakeholders that HEFCE and HEIs are making genuine efforts to promote sustainable development and to develop good practice and tools.

d. Support sector-led capacity building to pursue this agenda, based on existing frameworks and activity.

e. Stimulate national debate among stakeholders on those structural features of the English HE system that currently underpin its financial viability but which do not promote sustainable development, and to identify possible policy responses.
5. While we continue to believe in the value of developing tools to report organisations' progress on sustainable development, we are not seeking to introduce sector-wide reporting nor to penalise negative performance. In the short-term we will commission a strategic review of activity relating to sustainable development in the sector to demonstrate sector performance to stakeholders.

6. The proposed action around which there is most consensus is building on existing activity to share good practice and develop capacity. Accordingly, the strategic statement emphasises:

a. A commitment to continue to support the Higher Education Academy's work to identify, share and support the development of good practice in relation to sustainable development in the curriculum, in whatever form is appropriate.

b. An invitation to existing professional networks to submit proposals to the Leadership, Governance and Management Fund to develop capacity or good practice in sustainable development that would be of practical value to their professional activity.

\section{Action required}

7. This document is for information. 


\section{Introduction}

8. In January 2005 we consulted on a support strategy and action plan for sustainable development in higher education (HEFCE 2005/01). This document clarifies our approach to this new agenda, in the light of feedback received in the consultation exercise. An analysis of the written responses to the consultation is available on our web-site, with a summary of the main issues raised at our four regional consultation seminars (www.hefce.ac.uk/lgm/sustain/).

9. Overall, the feedback demonstrated:

a. A high degree of consensus that this agenda was important; that higher education (HE) had an important contribution to make to its delivery; and that HEFCE should have a role in facilitating the sector's activities in this area. With the marked exception of concerns around actions relating to the curriculum, the actions we suggested raised relatively little negative comment - though some were clearly prioritised over others.

b. A significant number of concerns about how we should promote this agenda, but with little consensus about the best way forward. Respondents had very different objections relating to, for example, their role within the institution, their philosophical approach to the agenda, and their views about the role of HEFCE.

c. Agreement regarding the potential contribution by the HE sector to sustainable development through institutions':

- role as educators

- generation and transfer of knowledge

- leadership of, and influence on, local, national and international networks

- business strategy and operations.

10. These findings could appear contradictory, but can largely be explained by two recurring themes of feedback:

- mixed views as to whether HEFCE's role is, or should be, steering or supportive
- a lack of clarity about what it means to engage more fully with the sustainable development agenda and what institutions are being asked to do.

11. To respond to the feedback, we have redrafted our original strategic statement, making efforts to:

- clarify our intentions in this area, including what we think our own role should be

- respond to concerns about what it means to promote sustainable development

- take account of the Government's revised strategy for sustainable development, 'Securing the Future', published during the consultation period: www.sustainable-development.gov.uk/ publications/uk-strategy/uk-strategy-2005.htm.

12. The original action plan represents a strenuous effort to promote a multi-dimensional perspective on how both the sector and HEFCE can contribute to this agenda. Based on feedback from the sector, we feel that this remains a valid statement, with the exception of recommendations relating to the curriculum. We therefore attach a slightly revised and updated version of the action plan at Annex A, as a companion to this strategic statement. There are three key revisions:

a. The removal of the proposal to 'explore with the Quality Assurance Agency, Universities UK (UUK) and the Standing Conference of Principals (SCOP) how a contribution to sustainable development could be used as an indicator of high quality taught provision'.

b. The insertion of a new action: 'To ask the Higher Education Academy, in the course of its ongoing work on sustainable development, to be alert to anything in the QAA precepts or codes that might work against including sustainable development in the curriculum, and if so to raise it with UUK, SCOP and the QAA.'

c. The inclusion of a new section on procurement, responding to feedback as well as to the high profile given to this issue in the Government's new strategy. The action arising is that: 'We will work with sector procurement bodies in order to develop sustainable procurement 
policies and guidance'. (This is in the second part of the action plan - 'Building the capacity of people to manage sustainable development'.)

13. The decision to remove the QAA-related proposal was in response to some significant concerns raised by this in the consultation. Specifically, respondents felt that the inclusion of this action represented:

- a covert attempt by HEFCE to establish itself as a planning body with a legitimate interest in academic strategy - and therefore a direct threat to institutional autonomy

- 'the State' selecting a particular social value (which some regard as a political ideology) to shape a university's curriculum, when there are arguably other equally 'worthy' agendas; which would represent a threat to overall academic independence.

14. The remainder of the action plan is broadly unchanged in light of support for most of the suggested actions ${ }^{1}$. However, we do not intend to pursue all these actions equally: following the consultation, we think some are more of a priority than others. That is why our strategic statement focuses on the priorities for action in the next two years and sets out a more concrete process for moving forward. We will review our progress by the end of 2007.

15. Throughout this document we refer to key features of the original support strategy on which we consulted, such as our principles of engagement, the role of HE in helping society to develop sustainably, and the four support roles set out for HEFCE through the action plan. However, for brevity, these concepts have not been explained in full here, so readers may wish to cross-refer to the original document.

16. Finally, we would like to thank all those who brought so much energy to the debates during the consultation. Many excellent ideas have been brought forward which we are unable to catalogue here, but which are feeding into our developing thinking. Nevertheless, we hope that respondents will recognise the impact of their views on this strategy and, more importantly, on the actions that follow in the next two years. We will also summarise the many activities to promote sustainable development that institutions reported engaging in, and will make these available to the sector by October 2005 .

\footnotetext{
1 We have removed case studies of institutional activity from this version of the action plan for brevity. These can be viewed in the original consultation document $(2005 / 01)$.
} 


\section{Strategic statement on promoting sustainable development in $\mathrm{HE}$}

17. We are clear that our role is to support individual institutions and the sector as a whole in meeting the challenge of sustainable development. At the same time we realise that integrating the sustainable development agenda into organisational behaviour is challenging, and must be done in a way that is sensitive to the direction of the organisation. In other words, we wish to help institutions find their own way forward in relation to this agenda rather than attempting to dictate one approach to the sector as a whole, or suggesting that all institutions should seek the same outcomes in the same way.

18. The problem with developing a 'support strategy' for the HE sector (as we referred to it in the consultation document) is that it can be inferred that we have a clear view of what we want the sector to be supported towards - that we have specific outcomes in mind that we have not yet stated. This perception allows the reader to extrapolate, and then possibly disagree with, what they think those desired outcomes are. It is simply not the case that we have a hidden agenda in relation to this issue. But we do understand why this confusion has arisen, because we are seeking to establish a 'supporting role' and at the same time to stimulate the debate.

19. We recognise that, while there is much room for disagreement about priorities and how this agenda should be implemented, there are nevertheless many uncontested areas, which makes it feasible for us to take immediate action. We are keen to incorporate as many of the different perspectives as possible - in consultation with the sector and taking full account of the distinctive missions of HEIs, as well as their preferred approaches to sustainable development. For this reason we have renamed this section as our 'strategic statement' on the sustainable development agenda. However, our desire to support the sector in this arena remains the same.

20. With the increasing profile being given to promoting the sustainable development agenda by the Government, as well as the international community, we believe it is important for us to demonstrate that both HEFCE and the English HE sector are moving forward on these issues. Because we believe that this is a critical social agenda, we do not think that maintaining the status quo is acceptable. The sector's strong endorsement of us taking an increased interest in this area suggests that others concur, despite different views on how sustainable development should be defined and the best way to engage with it. Accordingly, our vision statement remains:

'Within the next 10 years, the higher education sector in this country will be recognised as a major contributor to society's efforts to achieve sustainability - through the skills and knowledge that its graduates learn and put into practice, and through its own strategies and operations.'

21. How we tackle sustainable development in our own business is an important touchstone for us: we cannot invite the sector to do what we are unwilling to do ourselves as an organisation. So this strategic statement is about the approach to our own business as well as shaping the partnership we hope to develop with the sector. In arriving at our own way forward we recognise that some institutions are ahead of us in seeking to embed sustainable development.

22. Understanding the impact of our operations on the pursuit of sustainable development will require both raising awareness and building capacity within HEFCE as a whole. In this we hope to use the cross-Whitehall initiatives proposed in 'Securing the Future', as well as experience from within and outside the sector.

\section{HEFCE's aims and objectives}

23. In this initial two-year phase we believe our primary aim must be to build informed commitment to pursuing this agenda across all parts of the sector, including within HEFCE. We know that there is already considerable support within individual HEIs and believe that even more might be achievable if we sharpen our collective focus. We think the key to building this commitment is to develop a shared understanding of what success looks like in practical terms (this is discussed further below). 
24. More specifically, our objectives for this first phase of development will be to:

a. Seek 'win-win' opportunities for the sector to engage in this agenda by helping to identify sector-wide business cases as well as benefits for individual institutions.

b. Promote the value of engaging with the sustainable development agenda by integrating it in our policy-making processes and being open about the often hard choices made.

c. Demonstrate to stakeholders that HEFCE and HEIs are making genuine efforts to promote sustainable development and to develop good practice and tools.

d. Support sector-led capacity building to pursue this agenda, based on existing frameworks and activity.

e. Stimulate national debate among stakeholders on those structural features of the English HE system that currently underpin its financial viability but which do not promote sustainable development, and to identify possible policy responses.

25. Below we expand on what these objectives mean. The discussion is structured in three parts, based on what we think an attempt by HEFCE to engage more fully with the sustainable development agenda should look like:

- being more aware of the impact our business has on the sector as a whole

- $\quad$ supporting change sought by HEIs - because they are key shapers of social thinking as well as publicly funded bodies

- looking at how we operate as an organisation.

\section{The impact of HEFCE business on the sector}

\section{Mitigating potential negative impacts}

26. The original action plan takes some account of the impact our business has on the sector in terms of its financial stability and, for example, in the way we allocate capital. But we did not sufficiently acknowledge that integrating a concern for sustainable development with an organisation's mission and objectives is very challenging. (Although this was implicit in the two principles of engagement: 'building on existing activity' and 'being open about success and failure'.) We do recognise the challenges, and hope to allay institutions' fears that we will not take account of the diversity of their missions in encouraging them to embed sustainable development.

27. It is relatively straightforward to try to improve the way we allocate grants to achieve our strategic objectives - for example, to improve our capital allocation processes (a proposal in our original action plan). However, we face greater challenges when making more detailed decisions about how public funds are spent. Examples of the tensions we will face as a funding body trying to embed a concern for sustainable development in policymaking are:

a. Determining where we stand on seeking the balance between economic benefit in terms of value for money, and social and environmental sustainability.

b. More specifically, responding to institutions' bids to our Strategic Development Fund where the scenarios are, for example:

i. An institution's decision to re-focus its activity at a national rather than local level could imply a withdrawal of educational investment in local communities.

ii. The most cost-effective way for an institution to resolve an unstable financial situation could be to sell off existing lucrative estate and rebuild as cheaply (but perhaps non-sustainably) as possible on a green-field site.

c. Determining to what degree we can usefully generate a debate around some of the structures that currently underpin the sector's financial viability but which may not promote sustainable development, such as the global social and environmental impacts of the number of international students in England. 
28. One response to such tensions would be a categorical statement that gives precedence to either working towards the financial sustainability of the sector, or promoting sustainable development. In reality, we are much more likely to want to consider all decisions on their individual merits, having asked institutions to identify social and environmental impacts when seeking funding from us. This would be a key example of the need not to promote sustainable development as an over-arching, dominating priority, but instead to be more flexible and recognise that there are challenges in reaching decisions that require a positive, problem-solving approach. Over time we will experiment with what type of sustainable development 'model' allows us to make these decisions most effectively, and transparently (see paragraph 44).

29. To identify sustainability issues and to raise their profile within HEFCE, we will routinely appraise new policies through our own regulatory impact assessment process (reflecting our commitment to the principle of engagement that is 'questioning business as usual'). Applying this process in itself implies that there is no 'right' answer. The sustainability agenda will not automatically dominate decisions taken, just as a concern to reduce the accountability burden does not automatically dictate the final decision reached. Both, however, are among the key factors to be weighed up in arriving at decisions. We will try to be explicit about this thinking in consultation exercises, and we will also ask the sector to identify potential negative impacts of proposals.

30. By using 'test cases' and gathering further information, we will be able to explore the limitations of our actions to support sustainable development in the context of our strategic objectives.

\section{Encouraging positive impacts}

31. In summary, the discussion above reflects our commitment to try to identify where we are unwittingly encouraging unsustainable actions or discouraging sustainable ones. We have tried to indicate that we are concerned to moderate decisions to make them in some way 'less bad'; but promoting the sustainable development agenda is just as much about taking action that will have a positive effect.

32. For HEFCE, positive promotion of sustainable development could take a number of forms:

a. Developing, if possible, a set of metrics for institutions' community activities which could help drive allocations under the Higher Education Innovation Fund (a proposal in our original action plan).

b. Seeking to make the social and environmental, as well as economic, impact of policy proposals more visible in our advice to the Department for Education and Skills (DfES) and others. In this we need to acknowledge the current primacy of financial sustainability in policy frameworks, even as the Government is seeking to move towards convergence of these three goals. There is an opportunity to position $\mathrm{HE}$ as one of the leading sectors in working towards a more holistic framework.

c. Identifying the institutional benefits of embedding sustainable development - for example attraction of staff and students, staying ahead of regulation, global and local leadership in related knowledge and research, strengthening local relationships, and costsavings through efficient use of resources.

d. Developing good business cases with the help of the sector, seeking funds for HE that promote either:

- efficiency - by offering up-front investment in environmental practices in return for guaranteed longer-term savings

- or the public interest - so that institutions are supported in existing or expanded activities that make an important contribution to sustainable development. This could include, for example, supporting the HE contribution to the Government's aim of achieving 'sustainable communities', as set out in its recently revised strategy. 


\section{Supporting change sought by HEls}

33. The consultation exercise has led us to conclude that we need to support institutions in responding to this agenda by:

a. Concentrating on action, rather than continuing discussion about definitions, as a means of resolving differences in approach.

b. Directly addressing many institutions' fears that embedding a concern for sustainable development must imply treating it as an overarching priority that dominates decisionmaking and that will almost certainly be in conflict with the existing organisational mission.

\section{Concentrating on action}

34. Responses to our consultation document highlighted much agreement regarding the potential contribution by the $\mathrm{HE}$ sector to sustainable development. Common ground included supporting our proposals that HEIs could contribute through their:

- $\quad$ role as educators

- $\quad$ generation and transfer of knowledge

- leadership of, and influence on, local, national and international networks

- $\quad$ business strategy and operations.

35. Concerns about our original proposal relating to the QAA (see paragraphs 12-13) did not impact on the view held by the vast majority of respondents that promoting the 'educator' role is worthwhile - as evidenced by strong support for the activity led by the Higher Education Academy. The academy and its subject centres are working to identify and share good practice in education for sustainable development. This work is practitionerled, academically critical, and discipline specific; it builds on existing good practice in the sector and does not imply blanket adoption throughout subjects or institutions. We feel this activity will continue to be particularly valuable and the views of the sector confirm this.
36. We will continue to support this approach to curricular development through:

a. Our membership of the Sustainability Integration Group (SIG-net) set up by the DfES to promote an integrated approach to 'sustainability literacy' across the education sectors, and facilitated by Forum for the Future. UUK, SCOP, the Higher Education Academy and the Leadership Foundation are also members of SIG-net.

b. Our advice to the Department for Environment Food and Rural Affairs and the DfES in their efforts to develop 'an indicator to show the impact of formal learning on knowledge and awareness of sustainable development' - a commitment made in the Government's revised strategy for sustainable development.

37. The Higher Education Academy's initial work to identify good practice in relation to sustainable development in the curriculum is proceeding well, led by the subject centres. They have already identified much good practice relating to the integration of sustainable development in the curriculum, and are beginning to disseminate it across discipline communities. In future the subject centres will offer advice and support to academic departments wishing to enhance such provision through curricular and pedagogic development. They also propose to explore the possibility of greater connection between academics concerned with sustainability in the curriculum and individuals running environmental management systems within their institutions.

38. More generally, the academy will help disseminate the work of the HEFCE-funded Centres for Excellence in Teaching and Learning. Two centres directly target sustainable development and others might also make a contribution (HEFCE $2005 / 17)$. We will want to support the academy in its work in whatever form is appropriate.

39. While there was support for the HE sector as a whole contributing on all the four fronts identified in paragraph 34 , there were different views about the desirable balance of the four activities within any one institution, and whether we should consider focusing our support accordingly. Some believe that 
action directed at environmental protection (primarily through the management of the institution's estate) will deliver more outcomes, more quickly, than activity related to developing the curriculum. Others believe that institutions should, depending on their mission, focus more on one contribution than another. We recognise the legitimacy of both these views. At the same time we remain committed to promoting a view of sustainable development which is much wider than just environmental protection. Similarly, while institutions may choose to focus their activities on one dimension more than another, our approach will be to try to identify the business case for engagement in each and all of the four dimensions.

40. However, the biggest difference between respondents' views is less the issue of balance than what this implies for our working definition of sustainable development, and the practical actions arising. The consultation document says that we subscribe to the Brundtland ${ }^{2}$ definition of sustainable development, namely 'development which meets the needs of the present without compromising the ability of future generations to meet their own needs'. We also tried to explain the nature of sustainable development through a systems model which drew out some connections between natural capital (environment) and other forms of social and human capital. However, feedback suggested that these two together are insufficient as a definition of the outcomes sought, either at a sector or an institutional level.

The goal of sustainable development is to enable all people throughout the world to satisfy their basic needs and enjoy a better quality of life, without compromising the quality of life of future generations.

For the UK Government and the Devolved Administrations, that goal will be pursued in an integrated way through a sustainable, innovative and productive economy that delivers high levels of employment; and a just society that promotes social inclusion, sustainable communities and personal well-being. This will be done in ways that protect and enhance the physical and natural environment, and use resources and energy as efficiently as possible.
41. Objections varied enormously depending on the respondent's philosophical approach to the subject and/or their preferred approach to change management in this area. A sample of the criticisms were that this approach:

- emphasised the environmental ahead of the social aspects of sustainable development

- underplayed the global aspect of the sustainable development agenda, and in particular the economic links between developed and less developed economies

- was potentially inconsistent with the Government's revised framework

- was too theoretical and failed to set out clear outcomes sought

- $\quad$ ought to have a developed business case

- $\quad$ should be more value driven or was insufficiently value driven.

42. We understand why people have responded in this way, but we also believe that it is possible to interpret a high-level definition such as Brundtland to include these issues. To attempt to articulate a new, more detailed, exposition of the agenda on behalf of the sector as a whole would take time, and at the moment would not seem the best use of our resources. This is particularly the case since the UK Government's new strategy, published while we were out to consultation, has developed its original use of the Brundtland definition into a new 'purpose' as set out below.

Government must promote a clear understanding of, and commitment to, sustainable development so that all people can contribute to the overall goal through their individual decisions.

Similar objectives will inform all our international endeavours, with the UK actively promoting multilateral and sustainable solutions to today's most pressing environmental, economic and social problems. There is a clear obligation on more prosperous nations both to put their own house in order, and to support other countries in the transition towards a more equitable and sustainable world.

HM Government, 'Securing the Future', pages 15-17.

2 World Commission on Environment and Development (1987), 'Our common future: from one earth to one world'. 
43. This purpose is complemented by a set of five guiding principles used to achieve it, which should underpin all future policies:

- living within environmental limits

- ensuring a strong, healthy and just society

- achieving a sustainable economy

- promoting good governance

- using sound science responsibly.

44. However, we do think it is necessary for an organisation to determine its own way of moving forward, building on its own priorities, language and systems. The importance of 'owning' the agenda is also a general finding of the Higher Education Partnership for Sustainability (HEPS) ${ }^{3}$ programme, which used the 'five capitals' model to structure internal discussions. This model has been of value to the HEPS institutions and will be to others in future, but we recognise that some institutions may wish to use alternative models of sustainable development. Our primary approach will be to work through the European Foundation for Quality Management (EFQM) excellence model, but this will probably need to be supplemented by some form of sustainable development model, so we will need to experiment to achieve the best result.

45. We remain committed to placing equal emphasis on looking at the economic, social and environmental impacts of our actions. While it is critical to think about all of these issues in an integrated way, we do not assume that we can achieve them in equal proportion on every occasion. Integrating sustainable development in decisionmaking is a challenging process resulting in hard choices, and requiring stakeholders to engage in constructive discussion about options and outcomes in a positive and entrepreneurial way. That is why we place such emphasis on our principle of engagement that is 'being open about success and failure'. We will need to learn from our mistakes and adapt our approach over time, based on assessment of our overall achievements.
46. Over time it would of course be desirable for the HE sector, including HEFCE, to agree a working definition that overlaps with some, if not all, the different approaches to sustainable development. We hope to have a more informed discussion on this in a couple of years. In the meantime, we think the best way to create more shared understanding is to focus our energies on achievable actions around which there is most consensus. So while we propose to engage with all the actions set out in our plan over the next two years, we feel that our immediate task must be to support institutions where they are most in agreement. According to feedback, that is in building on existing activity to share good practice and to facilitate the development of capacity.

47. Therefore, we will make money available through the Leadership Governance and Management (LGM) Fund for projects initiated by the sector. In particular, we invite existing professional networks to submit proposals for funding to develop capacity or good practice in sustainable development that would be of practical value to their professional activity. In assessing any proposals we will look for significant crossinstitution collaboration within the professional community, as an indicator of 'buy-in' from the network as a whole.

48. A number of networks and partnerships have already made their interest in this area known via the consultation exercise. Others did not submit a group response. However, we are keen to see a variety of networks - relating to different types of responsibilities such as academic, administrative, and governance - engaging with these issues. We are also keen to:

a. Promote opportunities for links between different professional networks in respect of sustainable development projects. These could be, for example, between academics and administrators, between different aspects of university administration, and between HE staff and students.

\footnotetext{
3 Higher Education Partnership for Sustainability (HEPS) was a project funded through the Restructuring and Collaboration Fund. Further details are available at www.heps.org.uk
} 
b. Facilitate the early engagement of the Leadership Foundation and the Higher Education Academy with the development of network-led proposals. The aim will be, if appropriate, to shape some of the outcomes of the projects in a way that can be used in programmes delivered by these two organisations.

49. We note that these priorities target cross-sector rather than institutional structure change. This should have an impact on individuals and how they conduct their daily business, but it will not necessarily lead to the development of a strategic approach for the institution as a whole. This is one of the reasons we will need to review the impact of our approach by the end of 2007 .

\section{Addressing institutions' fears}

50. As noted above, many institutions fear that a concern for sustainable development will be an over-arching priority that dominates decisionmaking to the detriment of the organisational mission. Put another way, they feel they are being set up to fail - either in their own mission or in relation to the sustainable development agenda. Symptomatic of this is the relative lack of support for (as distinct from rejection of) the proposed action to develop reporting models - since that could make 'failure' more evident.

51. We hope that the discussion above of our own approach to the sustainable development agenda will do something to allay these fears. We believe the only way that we will succeed in promoting this agenda, internally and externally, is through looking for practical, attractive, value-adding steps towards objectives that people already wish to pursue. Indeed we believe that pursuing sustainable development is merely another facet of making a contribution to society, a dimension that forms a part of many HEIs' missions. But what we have not yet directly addressed is the question of how to report progress.

52. We understand the concerns, as we have yet to fully work through what this agenda means for our organisation. As noted above, we will need to learn from our mistakes and adapt our working practices over time, based on assessment of our overall achievements. But assessing our relative success or failure without benchmarking will be difficult. We hope that opportunities for benchmarking with similar organisations may arise as a result of the Government's new strategy.

53. Developing and subscribing to reporting methods is valuable to us because it:

- allows comparison with other organisations, which is motivating - whether because of a sense of achievement or by providing a clearer sense of the opportunity for improvement

- enables us to demonstrate to stakeholders that the HE sector is making progress in this area

- may help promote strategic change at the institutional level.

54. Although funding by performance would also be enabled by reporting tools, this is not one of our objectives. Our proposed support role of 'rewarding more sustainable behaviour' is aimed at rewarding positive behaviours rather than penalising negative performance, since that would promote neither buyin to the agenda nor a frank discussion of success and failure. It would be similarly unproductive to establish a single reporting tool, applied in a blanket way to all institutions, regardless of their mission and outlook. However it is possible that, over time, a preferred reporting method might emerge from within the sector just as it has from some parts of the private sector.

55. In contrast, our aim is to build commitment to pursuing sustainable development across all parts of the sector. We still think that reporting as a means of allowing comparison with similar organisations will promote better self-reflection and general understanding. So our action remains to 'support the testing of different sustainable development review methodologies to help us identify a mechanism or mechanisms to recommend to the wider sector'. We would be very interested in using the LGM Fund to support groups of HEIs that wish to develop reporting tools, and UUK/SCOP might be interested in taking a co-ordinating role in this activity. 
56. We acknowledge that some institutions will not wish to participate in the development of reporting tools, since they have still to see where engagement in this agenda might add value to their operations when set against the additional burden of monitoring progress and reporting. Through the consultation process we have also:

- gained a great deal more evidence about activity already under way in institutions that contributes to sustainable development

- listened to general concerns about the additional accountability burden of reporting.

57. So we will explore whether there is another means of demonstrating performance to stakeholders, while the value of institutional reporting is being assessed. We will therefore commission a light-touch strategic review of activity relating to sustainable development in the sector. Broadly this will aim to:

a. Establish a baseline of activity in the sector as a whole, against which we can identify trends over time and which we can use to publicise what the sector is already doing.

b. Learn from institutions' experience about what helps and hinders the embedding of sustainable development.

c. Identify key structural issues which currently underpin the sector's financial viability, but which may not promote sustainable development. We could then select a few of these for discussion with other stakeholders in order to identify possible co-ordinated policy responses. (The illustration of a 'structural' issue used above is the global social and environmental impacts of the number of international students in England.)

\section{HEFCE's own operations}

58. Our original action plan states that we will look at the operation of our own organisation, both to benchmark our key performance indicators on environmental management, and to develop an action plan for internal sustainable development which includes - but goes beyond - environmental management, to a more general approach to corporate social responsibility. Both these actions will be developed through our commitment to the EFQM excellence model, which should offer the best opportunity for embedding the promotion of sustainable development in our processes. 


\section{Action plan for sustainable development in HE}

1. This action plan sets out concisely and comprehensively a series of practical actions we propose to take. In most cases these actions are just the first steps on a long journey and not an end in themselves. Nevertheless we believe that implementing these commitments now will bring lasting benefits.

2. This plan is organised around the following four support roles identified in our original consultation document (HEFCE 2005/01). These are:

- engaging with stakeholders to bring about policy synergies on sustainable development

- building the capacity of people to manage sustainable development

- sharing good practice, or supporting the development of good practice where none exists

- rewarding more sustainable behaviour.

3. Under each role, the plan identifies a number of issues we think ought to be addressed and then describes the specific action to be taken. Although actions are listed separately under each objective, we intend that work in any area will inform work in others. A good example would be the work on curricula and pedagogy led by the Higher Education Academy, which we hope will encourage other stakeholders to introduce the principles of sustainable development into their various requirements.

4. The plan concludes with a section on what we will be doing to improve our own performance as a medium-sized business employing about 250 people. 


\section{Support role 1}

\section{Engaging with stakeholders to bring about policy synergies on sustainable development}

\section{Institutions exist in an increasingly} heterogeneous funding and regulatory environment. For every activity there is a range of stakeholder groups, each with their own responsibilities, interests and influence - and their own views on sustainable development. Any moves we or institutions take to pursue sustainable development must be developed through dialogue with these stakeholders. Otherwise we risk working at crosspurposes or failing to harness the forward momentum which already exists.

6. This section sets out what we will do to engage with stakeholders to make sure that does not happen.

\section{Developing curricula and pedagogy}

7. In our view the greatest contribution higher education has to make to sustainable development is by enabling students to develop new values, skills and knowledge. The main (though not the only) way to make this happen is through developments in curricula and pedagogy.

8. Below (paragraphs 39-40) we set out our proposals for supporting the Higher Education Academy to identify, share and augment good practice in curricular and pedagogical developments. We recognise, however, that other groups - including employers, professional bodies, quality assurance agencies and students - must also be engaged with this work, since these groups exercise such a great influence on what is taught and how. Equally important are teaching staff, who must be convinced of the benefits of new approaches, in a teaching and learning environment which has already seen great changes in recent years.
9. This points to a key role for HEFCE in engaging with a range of groups around the issues of curricula and pedagogy, and particularly in raising the demand among all parties for courses which develop the values, skills and knowledge to contribute to sustainable development. It will also be important for us to engage with people from other parts of the education system, including schools and further education, to identify how we can help each other promote teaching and learning about sustainable development at all stages.

Action: Building on the work of the Higher Education Academy in identifying, sharing and augmenting good practice in curricular and pedagogical developments, we will:

- build links to employers, professional bodies and students - all aimed at encouraging these groups to view sustainable development as a desirable component of higher education courses

- ask the Higher Education Academy, in the course of its ongoing work on sustainable development, to be alert to anything in the QAA precepts or codes that might work against including sustainable development in the curriculum, and if so to raise it with UUK, SCOP and the QAA

- continue to work with the Learning and Skills Council to ensure this activity meets the needs of institutions providing higher and further education. 


\section{Financial sustainability}

10. 'Sustainability' has often been given a rather narrow financial meaning in higher education. We now regard it as a much broader issue. Yet financial sustainability remains important, because we cannot expect institutions to embrace the long-term view on which a commitment to sustainable development is founded without some confidence in their own survival. A good example is the whole-life approach to building and refurbishment, which takes account of the costs of maintenance, refurbishment, renovation and demolition. The pay back on wholelife costing is proven, but takes place over decades.

Action: We will continue to work with partners, including the Treasury and the Department of Trade and Industry, and through initiatives including the Transparent Approach to Costing (TRAC), to promote the adoption of full economic costing and to pursue financial sustainability for English institutions.

\section{Capital funding}

11. In 2004-05 the Government allocated approximately $£ 816$ million in capital to higher education institutions in England. Capital funding has specific criteria governing how it is spent, and to this extent it is a useful tool for encouraging institutions to behave more sustainably in areas such as construction, which can exact a heavy environmental toll. (Our proposals for action on construction are laid out in the following sections.) However, we also recognise that capital funding may also hinder sustainable development because the associated deadlines for expenditure can militate against institutions taking new and innovative approaches. Again a good example is construction, where some institutions have argued that the strict deadlines associated with funding for the Science Research Investment Fund have made the risks of experimenting with more sustainable building too great.

12. This points to a need for greater flexibility in allocating capital funding. We already plan to increase flexibility by co-ordinating the allocation of learning and teaching, research and infrastructure capital and by reducing reporting requirements at project level. We are also exploring with our partners how we can improve our capital monitoring systems to provide institutions with greater flexibility and encourage longer-term planning, as indicated in paragraphs 50-52 of HEFCE 2005/08 ('Capital funding for learning and teaching, research and infrastructure: 2006-08').

Action: We will work with the Treasury, the Department of Trade and Industry and the DfES to secure improved longer-term capital planning by HEls, and improved capital monitoring systems, while providing institutions with greater flexibility.

\section{Minimising the accountability burden}

13. For us, and many other funders of higher education, sustainable development is a new responsibility. As such it will lead to changes in our information requirements, so that we can gain a sense of how the sector is performing. However, we recognise the risk that new information requirements may either add to what is already in some areas an overly-burdensome accountability framework; or may skew priorities by imposing a set of indicators that are regarded as ends in themselves and not as indicating progress towards sustainable development. Thus it is vital for us to work with other interested bodies to devise a coordinated approach.

Action: We will work with other stakeholders committed to sustainable development to co-ordinate any associated reporting requirements.

14. More broadly, disproportionate accountability requirements in all areas could impede the transition to sustainable development if they consume resources which could best be applied elsewhere. We have worked hard over recent years to make sure our accountability requirements are consistent with the five principles of good regulation set out by the Government's Better Regulation Task 
Force. ${ }^{4}$ This work has included a reduction in both the value and number of different special funding streams; changes to the assessment of teaching quality; and reforms to the audit code of practice. A recent report by PA Consulting showed that these changes and others have resulted in a 25 per cent decrease in real terms over the period 2000-04 in the total funds spent by institutions on accounting for HEFCE funds. ${ }^{5}$

15. However, we are mindful that there is always room to improve and we are committed to working with a range of stakeholders, including the new Higher Education Regulation Review Group.

Action: We will work with stakeholders, in particular the Higher Education Regulation Review Group, to ensure our reporting requirements continue to be consistent with the five principles of good regulation.

\section{The regional level}

16. The ties between institutions and their regions are strengthening, helped by the creation of the Regional Development Agencies (RDAs). Regional issues are also becoming important for HEFCE, particularly in widening participation where we see regional lifelong learning networks as a key part of helping non-traditional students to participate in higher education.

17. The RDAs have been asked by Government to draw up sustainable development strategies for their regions. These strategies will affect their relationships with institutions. There is an opportunity here to bring about synergies between the RDAs and HEFCE in regional higher education policy.

Action: We will work with the RDAs to bring about policy synergies around sustainable development.

\section{Research}

18. Our role in supporting research in higher education can broadly be described as providing funds for the underpinning research infrastructure, which includes the salaries of permanent academic staff, premises, libraries and central computing costs. These funds are the basis for the pursuit of basic 'blue skies' research and project work. They are spent at institutions' discretion: it does not normally fall within our remit actively to encourage particular forms of research.

19. However, as is clear from our vision, we believe that the higher education sector has an important contribution to make to sustainable development through its research activities across the subject spectrum. Hence we now wish to explore with the Research Councils and other research funders whether these research efforts could be strengthened.

Action: We will explore with the Research Councils and other research funders whether research could be strengthened to build the new skills, knowledge and tools needed for sustainable development in all subject areas.

\footnotetext{
4 www.brtf.gov.uk

5 PA Consulting (2004), 'Better accountability revisited: review of accountability costs 2004', on the web at www.hefce.ac.uk under Publications/R\&D reports.
} 


\section{Support role 2 \\ Building the capacity of people to manage sustainable development}

20. In the previous section we set out the first round of actions we will take to bring about policy synergies on sustainable development among major funders of higher education and other stakeholders. We believe these actions are crucial, but they are not enough by themselves. Institutions are equally important players in developing policy. They need to demonstrate a willingness to pursue sustainable development so that other bodies, including funders, see it as a high priority for the sector.

21. The next three sections set out our first-round actions for helping the higher education sector to do this, with a particular emphasis on areas where we have an established strategic and/or financial interest. This section deals with our approach to supporting the development of skills required to manage sustainable development.

\section{Leadership}

22. Leaders have a crucial practical role to play in supporting the transition to sustainable development, by guiding institutions' strategic planning, managing major capital programmes and leading the institutions' interactions with external stakeholders. Leaders also have a symbolic role in influencing the views of staff and students about sustainable development. Thus it is important that leaders have the skills to take decisions which are compatible with this agenda.

23. In developing this action plan we have talked with many leaders, including members of our own external advisory group and the UUK/SCOP group on sustainability, and those attending the 2004 HEFCE Conference. These discussions have demonstrated a broad consensus about the need for sustainable development and about the contribution higher education has to make. Against this commitment, however, lies a range of apparently competing responsibilities, not least institutions' financial performance.

24. This points to a need for more support for leaders in integrating the principles of sustainable development into other established processes. We are pleased that the Leadership Foundation has identified sustainability as one of its 15 key strategic challenges for higher education, and is designing elements of its Top Management Programme around this agenda.

Action: We will continue to support the Leadership Foundation in embedding sustainable development in its courses and programmes.

\section{Management}

25. Sustainable development is a process of learning new skills and knowledge. This process is as applicable to staff as to students. Only institutions that give staff the opportunity to develop and use new skills will be able to manage sustainable development successfully.

26. We regard our investment in people management - primarily through the Rewarding and Developing Staff in HE (R\&DS) initiative - as a catalyst in the transition towards sustainable development. We assume that institutions are committed to continuous improvement in their people management, which carries with it a reasonable requirement to review and assess current activity and progress. To this end, the sector's own professional HR bodies (the Universities Personnel Association and the SCOP Personnel Network), in consultation with HEIs and key stakeholders, have developed a self-assessment tool, which enables HEIs to measure practice and performance in people management in a systematic and evidencebased way. The tool is on the web at www.hefce.ac.uk/lgm/hr, and can be completed online.

27. Managing sustainable development will also require people to learn new skills and knowledge and to combine these with a range of different perspectives. Key here are HR processes that prioritise skills and competencies regardless of age, sex, ethnic background, religion or sexual orientation; and the maintenance of a diverse workforce which represents society and the student 
population. The work of the Equality Challenge Unit, jointly funded by HEFCE to encourage institutions to promote diversity and equality of opportunity, will continue to be important in this regard.

Action: As catalysts in the transition to sustainable development, we will continue to:

- allocate funds through the Rewarding and Developing Staff initiative

- support the implementation of the self-assessment tool for people management

- support the Equality Challenge Unit.

\section{Construction and refurbishment}

28. The total estate of the English higher education sector has been measured at 24.6 million $\mathrm{m}^{2}$. The buildings that make up this vast estate have a heavy impact on the sustainability of the natural environment. Construction in general accounts for 40 per cent, or 3 billion tons, of the total flow of raw materials into the global economy every year. Then there are impacts associated with the use and maintenance of buildings, particularly the energy needed to heat and light them, and finally the waste produced by demolition.

29. Modern construction and refurbishment methods make it possible to significantly improve the impact of buildings while also reducing lifetime costs and improving the experiences of occupants. These methods are becoming increasingly popular, which is evident from new standards in the construction of schools and hospitals. There are examples of leading-edge construction in the higher education sector (www.heepi.org.uk/green_gown_award_winners.htm). And Annex C of HEFCE 2005/08, 'Capital funding for learning and teaching, research and infrastructure: 2006-08' gives references to a wide range of good practice, including on sustainable construction.

30. We believe there is a strong case for higher education to adopt these new methods of construction and refurbishment, so that more sustainable buildings become commonplace. To help achieve this, alongside our actions on capital funding set out in paragraphs 11-12, and in partnership with the sector's representative bodies, we propose to fund activity aimed specifically at boosting the sector's own capacity to manage more sustainable buildings. This activity will include enhancements to the Estates Management Statistics service, and support for the development of building assessment methods.

Action: In partnership with representative bodies, we will fund activity aimed at building the sector's capacity to manage more sustainable buildings.

\section{Procurement}

31. The total non-pay spend in the English higher education sector is $£ 4$ billion per annum.

Procurement decisions about works, goods and services affect the rate of consumption of resources, and the productivity of resources, as well as influencing the social and environmental impact of institutions and companies in the supply chain.

32. Staff involved in procurement must be aware of the environmental pressures on the supply of goods and services. New environmental regulations may also affect supply, and alternative sources may need to be found to guarantee continuity.

33. Companies in the supply chain who do not act in a socially responsible way are a risk to higher education institutions through discontinuity of supply and adverse media coverage. Procurement staff must be aware of such risks in order to manage them effectively.

34. Cost savings are a key aspect of efficient and effective procurement, but these should be based on whole-life costs, including those of disposal. For example, the costs of using landfill sites are rising, and disposal of hazardous waste is increasingly governed by EU directives. The most effective way of managing these costs is to recognise them at the point of purchase and to factor them in to wholelife costs. Following the completion of the Gershon 
Review to improve public sector efficiency, we have raised with the Government the importance of achieving its recommendations alongside a commitment to sustainable procurement.

35. Procurement in higher education can stimulate markets for goods and services with reduced negative or even positive environmental impacts. This would build on higher education institutions' reputation for corporate and social responsibility, enhance their public image, and perhaps provide public relations opportunities.

Action: We will work with sector procurement bodies to develop sustainable procurement policies and guidance. In doing this we will draw on any guidance developed by the Cabinet Office following the recommendations on improving public sector efficiency from the Gershon Review. 


\section{Support role 3}

\section{Sharing good practice, or supporting the development of good practice where none exists}

36. In developing these documents, we have met a large number of people working in higher education who are sympathetic to sustainable development but apparently lack the means and support to put it into practice. In fact, there is a wide range of advice available, as well as case studies of how this advice can be implemented, but the response of many of the people we talked to indicates that this advice lacks visibility or credibility. There are also other areas, for example curricula and pedagogy, where guidance is sparse and needs to be built up.

37. In this section we address the challenge of building, sharing, and testing the applicability of good practice through a number of different actions. All these actions will be signposted centrally from the section of our web-site devoted to sustainability. Over time the site will be developed to provide further guidance and tools.

\section{Developing curricula and pedagogy}

38. Our view is that the greatest contribution higher education has to make to sustainable development is through the values, skills and knowledge that its graduates learn and put into practice. Ironically this is the one area where good practice may be weakest. This points to a need for HEFCE to support the development of curricula and pedagogy.

39. In $2004-05$ we provided $£ 1.1$ million to the Higher Education Academy to address a number of specific priorities, one of which is developing a programme for identifying, sharing and augmenting good practice in learning about sustainable development. We have asked the Higher Education Academy to ensure that its programme can be applied to HE delivered in further education colleges. More information is available on the academy's web-site, www.heacademy.ac.uk under Thematic work/Curriculum.

40. Earlier this year we published the outcomes of the exercise to identify Centres for Excellence in Teaching and Learning - CETLs (HEFCE 2005/17).
We are now funding two projects which directly address the issue of sustainable development, at Kingston University and the University of Plymouth. The Higher Education Academy will be helping to disseminate the CETLs' work. More information on the projects can be found at www.hefce.ac.uk under Learning and teaching/CETLs.

Action: We will support the Higher Education Academy in identifying, sharing and augmenting good practice in learning about sustainable development.

\section{Sharing existing good practice}

41. We are not aware of a higher education institution anywhere in the world that has managed to adopt in a holistic way the principles of sustainable development. But there is a substantial body of good practice guidance on improving particular functions which can help institutions to begin the transition. This guidance tends to be strongest in areas such as energy efficiency and waste management, where challenges are common to other sectors and where there is a financial incentive to improve. More recently we have seen the emergence of guidance dedicated to the HE sector, including through the Higher Education Partnership for Sustainability, in areas such as purchasing and financial management where good practice relating to sustainability is less developed.

42. To make this good practice more visible, and to encourage its uptake, we are developing the sustainability section of our web-site to provide signposts to a wide range of information on, for example:

- curricula and pedagogy

- construction and refurbishment

- environmental management systems

- purchasing and procurement

- travel, transport and accessibility 
- $\quad$ resource and asset management

- communications.

43. We will work with representative bodies to ensure this guidance is consistent with their needs and with professional good practice.

Action: We will build and maintain a section of our web-site dedicated to raising the visibility of existing good practice on sustainable development, in partnership with other bodies.

\section{Building new practice}

44. While a substantial amount of good practice exists, there are areas where it is either considered incompatible with higher education or absent altogether. There is also the challenge of taking a range of isolated functions and cross-fertilising them with other functions, leading to a more holistic approach to sustainable development.

45. In these areas we recognise a role for HEFCE: to facilitate testing the applicability of good practice drawn from other sectors; to facilitate building good practice where none exists; and to help institutions explore how sustainable development can be embedded holistically within management systems. To undertake this role in the first instance we will invite applications to our LGM Fund, which is aimed at encouraging the development of good practice and providing measurable change in the quality of management and organisational performance.

46. Proposals can be made to the LGM Fund at any time until July 2007 (see HEFCE 2004/26 for details). Successful applications will be publicised through our web-site.

Action: We will invite applications to the Leadership, Governance and Management Fund aimed at developing good practice in sustainable development.

\section{Carbon management}

47. There is now international scientific consensus that the climate is changing, and that people have a role in accelerating it. Most scientists agree, however, that the worst effects of climate change might be minimised if emissions of greenhouse gases such as carbon dioxide are dramatically reduced. The UK Government has responded by committing to a 60 per cent reduction in greenhouse gas emissions by 2050 .

48. One of the Government's delivery agents for this emissions target is the Carbon Trust. The role of the trust is to help UK business and the public sector meet ongoing targets for carbon dioxide emissions, to support the development of UK-based low carbon technologies, and to increase business competitiveness through resource efficiency. Through its carbon management programme the trust works in partnership with organisations to develop robust carbon management strategies and implementation plans. Through a number of pilot projects, it has identified higher education as a fertile sector for the introduction of carbon management, because of the sector's huge total consumption of energy and its interactions with students. The trust is now working on the development of a carbon management programme for higher education.

49. We view the adoption of carbon management as one way in which institutions can begin the transition to sustainable development. It is also an ideal way of demonstrating this transition to external stakeholders, including funders and students. Thus we are supporting the Carbon Trust's work to test its carbon management programme among a pilot group of institutions in 2005-06. You can find out more about the programme and the support available at www.thecarbontrust.co.uk or by e-mailing Richard.Rugg@thecarbontrust.co.uk.

Action: We will work with the Carbon Trust in supporting a pilot group of institutions to develop, test and refine a carbon management programme for $\mathrm{HE}$. 


\section{Research and evaluation}

50. The actions set out in this plan constitute the first round of our activities in sustainable development. The success of subsequent activities will depend on a much greater understanding of the parameters of sustainable development in higher education and how it connects to other agendas. In some senses these connections are unknowable before the implementation of this plan and other events, including the introduction of top-up fees in 2006. But it is important that we begin to commission research now aimed at broadening our knowledge and identifying priority areas for future work.

51. Our first research project will be an evaluation of the impact of the Higher Education Partnership for Sustainability which we funded (with the other HE funding bodies) through our Restructuring and Collaboration Fund between 1999-2000 and 2002-03. The aim of this project was to establish a partnership group of HEIs who were achieving strategic objectives through positive engagement with the sustainable development agenda and could help generate tools and guidance for the rest of the sector. The project outcomes are set out in the final report, available at: www.forumforthefuture.org.uk/ publications/HEPSfinalreport_page1828.aspx.

Action: We will commission research and evaluation projects exploring the barriers to sustainable development in higher education and how these might be overcome. 


\section{Support role 4}

\section{Rewarding more sustainable behaviour}

52. In keeping with the principles of engagement set out in the original support strategy on which we consulted, it is our aspiration to reward more sustainable behaviour mainly through core funding and not through special funding initiatives which, by definition, are short-lived. We view this as an aspiration because it is a long-term, incremental process which depends on a number of variables, in particular:

- the co-operation and support of a range of other stakeholders, including institutions themselves

- the development of transparent, robust and efficient measures with which institutions can give a sense of performance and improvement.

53. We will begin this process through three actions: forging stronger links with the community, facilitating the taking of a more sustainable approach to managing the higher education estate, and encouraging reporting on sustainable development.

\section{Stronger links with the community}

54. Many institutions have long-established ties to their surrounding communities, founded on what they regard as a responsibility to strengthen the social fabric which surrounds and supports them. A good example of this is staff and students doing voluntary work for local community groups. We recognise the importance of this role and support it through our 'third stream' funding to encourage links between HE and business and the community.

55. Although rarely described in these terms, implicit in much of this community work are some of the principles of sustainable development, and particularly the objective of maintaining local social capital. As such we believe this work ought to become a permanent part of all institutions' strategy and operations, formally recognised and funded by HEFCE and other bodies. As part of preparing for the third round of the Higher Education Innovation Fund, we intend to develop a set of metrics for community activities. If suitable metrics can be identified, they will be used to drive funding allocations.
Action: We will develop a set of metrics for institutions' community activities. If suitable metrics can be identified, they will be used to drive funding allocations under the Higher Education Innovation Fund.

\section{A more sustainable approach to managing the estate}

56. In the first and second sections of this plan we proposed, respectively, changes to capital funding and a programme to facilitate the building of capacity in managing more sustainable construction. In the medium term, changes to the way capital funding is allocated could also include introducing a self-assessment methodology, with a strand focusing on the sustainability of infrastructure. We plan to consult Government and sector bodies on this new approach during 2005 .

57. The self-assessment methodology will be a balanced view across all the management functions undertaken by those with a remit for estates, infrastructure and facilities. As each institution is structured differently this will, by necessity, look at high-level strategic issues relating to sustainability of the physical environment. It will take into account the identification of risks, the levels of investment, and the links to the corporate plan.

58. The incentive for securing successful selfassessment could be increased flexibility in the use of capital funding from HEFCE. To reach and maintain this lower level of scrutiny by HEFCE, institutions would also need to develop acceptable infrastructure strategies designed to sustain the physical infrastructure in a fit state for the longterm; and demonstrate that capital investment was actually taking place, in accordance with those strategies.

\footnotetext{
Action: We will support the development of good practice for estates, from which the self-assessment methodology will derive. The methodology will be developed to enable institutions to give the necessary assurance to stakeholders, and will incorporate suitable arrangements for verification.
} 


\section{Reporting on sustainable development}

59. One of the barriers we face to rewarding more sustainable behaviour is the apparent lack of a suitable reporting mechanism for higher education. This is in contrast to the private sector, where a number of independent reporting mechanisms exist to help companies disclose their social, environmental and ethical performance; to compare it with the performance of their competitors; and to identify areas for improvement. These mechanisms are seen as key to the progress made by many companies over recent years.

60. Developing one or more reporting mechanisms for HE is important. Our aspirations for any mechanism are that it must be transparent and generate consistent and auditable results, but at the same time be consistent with our principles of engagement. In particular it should respect institutional autonomy and diversity, complement institutions' existing systems and structures, and facilitate a process of genuine reflection and improvement - not one of secrecy and competition.

61. With these criteria in mind, we would like to support several institutional groupings in testing different review and reporting methodologies, which will help identify a mechanism or mechanisms to recommend to the wider sector.

Action: We will support the testing of different sustainable development review and reporting methodologies to help us identify a mechanism or mechanisms to recommend to the wider sector.

62. In time we will wish to consider whether these mechanisms should be embedded within our formal relationships with institutions. We could, for example, ask institutions to publish an annual statement on their performance, rather like the corporate social responsibility statements published by many listed companies as part of their annual accounts. Alternatively we could ask institutions to use their corporate plans to set sustainable development priorities and then monitor performance against these priorities through the annual monitoring statement submitted to us. A third and perhaps more attractive possibility is for institutions to demonstrate their work on sustainable development as part of institutional risk management, building on our approach to estates good practice.

\section{The next HEFCE strategic plan}

63. Finally we turn to the issue of what will happen once the actions in this plan have been achieved. In our vision of higher education's contribution to sustainable development, we signalled our commitment to 'make sustainable development a central part of our strategy for the future development of the higher education sector'. We believe that implementing the actions in this plan now will bring lasting benefits. However, making sustainable development a central part of our strategy demands a more co-ordinated and holistic approach than is possible with a single plan. So we intend to make sustainable development a key theme of the next HEFCE strategic plan, published in 2006.

\section{Actions for HEFCE}

64. We recognise that we need to begin our own transition to sustainable development. This will bring benefits to the environment and to our local society and will also help us to learn first-hand about the financial and social parameters of sustainable development. This should help, in turn, to inform our outward-facing activity in this area.

65. HEFCE is a medium-sized organisation employing about 250 people and based on two separate sites: a headquarters in north Bristol and a small office in central London. Our performance as an organisation has a major impact on how $£ 6$ billion of public money is spent each year, how well it is accounted for, what outcomes the spending delivers, and how far value for money is secured. To discharge these responsibilities we must be a learning organisation with a culture of continuous improvement, and we attach a high priority to supporting and developing our people. This is evident in our re-recognition as an Investor in People; our achievement of EFQM level 1 'committed to excellence' (by 2008 we aim to have achieved level 2 'recognised for excellence'); and our proactive stance on equality and diversity. 


\section{Environmental management}

66. Our culture of continuous improvement is echoed in our environmental policy. This aims to meet the highest standards of environmental management, including in recycling, transport, procurement and contract management. Our Green Transport Plan - including car sharing and cycling to work, and the use of video-conferencing to avoid travelling to meetings - recently won an award from the local authority. We also have a voluntary staff Environmental Action Group and we are a corporate member of the Woodland Trust.

67. We believe the actions outlined above represent a genuine commitment to minimising our impact on the natural environment, but until now we have not had a set of environmental performance indicators to give us a holistic idea of progress, or a comparison with similar organisations. In keeping with our principles of engagement on sustainable development, and in particular our commitment to be open about success and failure, we have recently developed such indicators. These will be available on the sustainable development section of the HEFCE web-site. Furthermore, we have committed to benchmark these indicators against similar organisations and to pursue year-on-year improvements in all categories. We will also publish the indicators in our annual review. Our aspiration is to become recognised as a leader in environmental management among organisations of our size and function.

Action: We will benchmark key performance indicators on environmental management against similar organisations and pursue year-on-year improvements in all categories. Our aspiration is to become recognised as a leader in environmental management among organisations of this size and function.

\section{Other elements of sustainable development}

68. Our contribution to some of the other elements of sustainable development, such as the social cohesion of our local community, is perhaps not as well articulated as our contribution to environmental management. In fact our staff undertake a range of activities, including recycling computers to local charities, using team awaydays to help the local community, and charity fundraising. Some activities are undertaken voluntarily and some under the auspices of HEFCE.

69. We do not wish to devalue individuals' initiative by taking a centralist approach to sustainable development in all areas, but we recognise that there is much more we could be contributing as an organisation beyond environmental management. We therefore commit ourselves to developing a holistic action plan for internal sustainable development which includes, but is not confined to, environmental management. The prosecution of this plan will be an important part of our commitment to excellence in delivery in the next HEFCE strategic plan.

Action: We will publish a holistic action plan for internal sustainable development. 


\section{List of abbreviations}

CETL Centre for Excellence in Teaching and Learning

DfES Department for Education and Skills

EFQM European Foundation for Quality Management

HE Higher education

HEFCE Higher Education Funding Council for England

HEI Higher education institution

HEPS Higher Education Partnership for Sustainability

LGM Fund Leadership Governance and Management Fund

QAA Quality Assurance Agency for Higher Education

R\&DS Rewarding and Developing Staff in HE initiative

RDA Regional Development Agency

SCOP Standing Conference of Principals

SIG-net Sustainability Integration Group

UUK Universities UK 
Higher Education Funding Council for England Northavon House

Coldharbour Lane

BRISTOL

BS16 1QD

tel 01179317317

fax 01179317203

www.hefce.ac.uk 